\title{
Fatigue Behaviour of Nitrided En41A Nitralloy Steel
}

\author{
Dr. Abbas A-Hussein Al-Taee* \\ E-mail: abbasaltaee@yahoo.com
}

\begin{abstract}
It has been recognized that the fatigue properties of metals are greatly affected by the surface condition. In steel parts a marked improvement in fatigue performance can result from the formation of hard layer on the surface. The processes commonly used for surface hardening are nitridig and carburizing.

The reason for such improvement is attributed to the formation of compressive residual stresses in the hardened layer. Nitriding processes produce higher hardness, hence induces higher compressive residual stresses., which effectively increase fatigue performance.

In this work, a mixture of $\left(\mathrm{NH}_{3}-\mathrm{H}_{2},\right)$ gas was used for nitriding fatigue specimens of En41 A steel. The effect of nitriding condition such as, temperature, ammonia content., nitriding time, hardness, microstructure and the depth of nitrided layer was investigated. The results from fatigue tests were discussed and related with the hardness and the nature of microstructure of nitrided layer. It was found that higher hardness without the formation of Iron-nitride layer ( white layer) gives better fatigue properties.
\end{abstract}

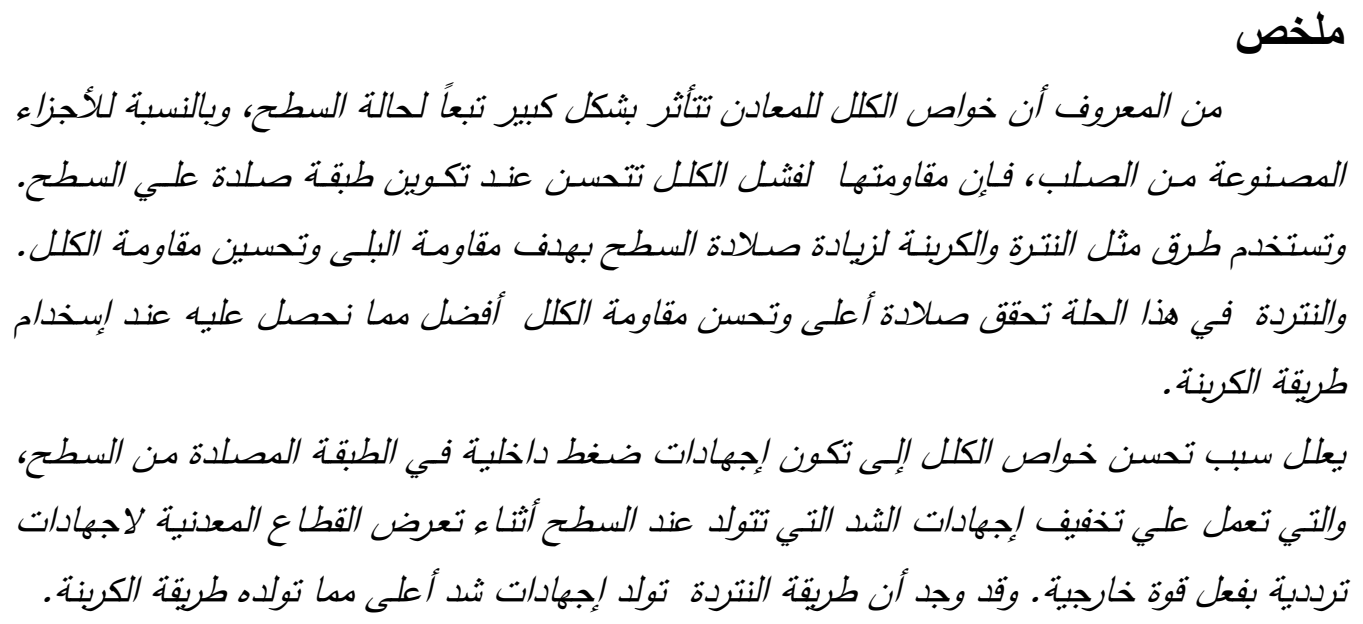

"Faculty of Engineering Sciences-Omdurman Islamic University. 
في هذا البحث إعتدت طريقة النتردة الغازية لإصلاد سطح صلب من نوع En41A وذلك

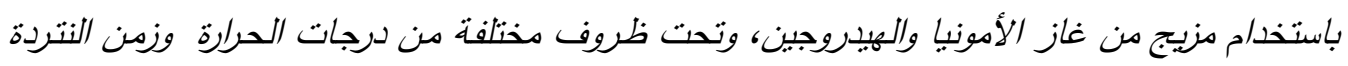

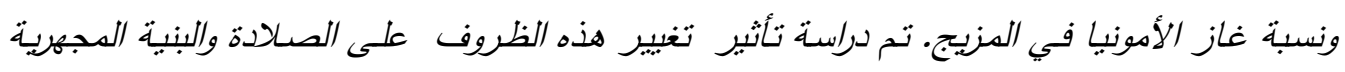
وعمق الطبقة المنتردة، وعلي ضوء ذلك تمت مناقثة نتائج فحص الكلبل. وقد وجد أن الظروف التي تؤدي أعلى صلادة وبدون تكون طبقة تتربيد الحديد علي السطح والدعروفة باسم الطبقة البيضاء، سوف تعطي أفضل الخواص لئقاومة الكلل. 
مجلة العلوم الهندسية_العدد الثاني-2006

\section{Introduction}

Early investigations showed that the endurance properties of nitrided steel under an alternating stress were greatly enhanced $(1,2)$. The major benefit becoming more apparent in specimens having stress raisers, such as notches, bores or rough machined surfaces, implying that nitrided steel parts have higher notch resistance. This is important since fatigue properties are highly sensitive towards notches and surface finish. However, regarding the effect of nitriding on the direct stress fatigue behavior there have been some conflicting reports. Sutton (3), Bardgett (4). Cazaud (5) and Tauscher et al. (6), all reported that nitrideing has little effect on the direct stress fatigue limit, whereas investigations by Jones and Martin (7), carried out on En41B indicate that nitriding does significantly improve the direct stress fatigue limit. It has been shown however that the fatigue limit increase with increasing case / core area ratio, and the increase in fatigue limit was reduced with increasing nitrideing time. Jack and Winnik (8) investigated En19 steel using Rolls-Royee type rotating-bending fatigue specimen. It was concluded that fatigue resistance depends on residual stress in the case, and not on the microstructure of the case or the presence of surface iron nitrides.

\section{Material and Experimental Methods}

The material used for this work was En41A steel whose composition is given in Table (1) specimens were machined from material which had been oil quenched from $900 \mathrm{C}$ then tempered at $600 \mathrm{C}$ for $1 \mathrm{~h} . .$. All specimens were smoothly hand polished then electro polished to remove the fine scratches from the surface. The tests were carried out using Rolls-Royee type rotating-bending fatigue specimens, and it was performed on a Wohler rotary bending machine at a speed of 2800r.p.m. The fatigue specimen dimensions are shown in Fig. 1.

Five sets of specimens were tested; three sets were nitrided at different conditions for different times. The aim being to achieve the same case depth in the three nitriding conditions, but with different hardness profiles, and with or without surface iron nitride. Table (2) summarizes the data from each nitriding condition.

The other two sets of specimens were tested in the quenched and tempered condition; one set was first tempered at $600 \mathrm{C}$ forlh then aged at 
$570 \mathrm{C}$ for $48 \mathrm{~h}$ to simulate the core condition of the specimens nitrided at $570 \mathrm{C}$ for $48 \mathrm{~h}$.

The fracture surfaces were examined by both optical and electron microscopy.

\section{Hardness and Depth of the Nitrided Case}

The micro hardness profiles obtained for the different nitriding conditions are given in Fig. 2. At $520 \mathrm{C}$ a steep profile and a maximum harness of $1100 \mathrm{VHN}$ was achieved in $80 \% \mathrm{NH} 3$. in $30 \% \mathrm{NH} 3$ for $48 \mathrm{~h}$ the profile is less steep with a greater hardening depth, but the maximum hardness remains tha same. However nitriding at $570 \mathrm{C}$ in $10 \% \mathrm{NH} 3$ for $48 \mathrm{~h}$ produced a shallow hardness profile and a maximum hardness of $\sim 900 \mathrm{VHN}$.

The difference in core hardness between specimens nitrided at $570 \mathrm{C}$ and those nitrided at $520 \mathrm{C}$ is small (approximately $30 \mathrm{VHN}$ ), see table 2.

The specimens nitrided at $570 \mathrm{C}$ in $10 \% \mathrm{NH} 3$ and $520 \mathrm{C}$ in $30 \% \mathrm{NH} 3$, are both free of white layer (surface iron nitride), and the specimens nitrided at $520 \mathrm{C}$ in $80 \% \mathrm{HN} 3$ contain white layer of thickness approximately $25 \mathrm{um}$. Formation of the white layer can be controlled by changing NH3 concentration in the $\mathrm{NH} 3: \mathrm{H} 2$ gas mixture.

\section{Fatigue test and $\mathrm{S}-\mathrm{N}$ curves}

The fatigue properties of a given material can be conventionally expressed in the from of S-N curves, where $\mathrm{S}$ is the amplitude of stress to produce fatigue failure after $\mathrm{N}$ cycles. The rotating bending fatigue test (Wholer test) is a common method used for cylindrical specimens.

The S-N curves were obtained from tests using a minimum of 8 specimens for each condition (plain and nitrided). Owing to the statistical nature of the fatigue process and the consequent scatter of results, the number of the tests carried out in the present investigation was considered small, and as a result some deviation from an average curve in each condition is to be expected. However, S-N curves really represent some kind of average for the specimens tested. 
مجلة العلوم الهندسية_العدد الثاني-2006

\section{Fatigue Test Results}

The result from the fatigue testing program are shown in Fig. 3 for the non-nitrieded and nitrided specimens. For the nitrided specimens, it is apparent that the improvement of the fatigue properties are very much dependent on the nitriding conditions. Nitriding at $520 \mathrm{C}$ in $30 \%$ and $80 \% \mathrm{NH} 3$ improves both fatigue life and fatigue limit. The fatigue life at $900 \mathrm{MPa}$ increased from 40000 to between $60000-600000$ and he fatigue limit was raised from $625 \mathrm{MPa}$ to between 800-850 $\mathrm{MPa}$, approximately a $25 \%$ increase. Also the fatigue strength was improved by an average of $30 \%$, a value which is close to that previously reported in larger cross section specimens (9).

The fatigue properties of specimens nitrided in $30 \% \mathrm{NH} 3$ for $48 \mathrm{~h}$ are slightly better than those nitrided in $80 \% \mathrm{NH} 3$ for $24 \mathrm{~h}$, the specimens in both cases have the same maximum surface hardness and the same core hardness with similar hardness profiles, but the hardening depth is grater in the former condition by about $20 \%$, and this could be the reason for the small improvement in the fatigue performance, because the extent and the magnitude of the compressive stress would be better in this case.

On the other hand, the fatigue properties of the specimen nitrided at $570 \mathrm{C}$ in $10 \% \mathrm{NH} 3$ are inferior to those produced by nitriding at $520 \mathrm{C}$ in $30 \%$ or $80 \% \mathrm{NH} 3$, if compared with the performance of the as-tempered specimens, the fatigue limit where nitriding at $570 \mathrm{C}$ in $10 \% \mathrm{NH} 3$, is unchanged, but the endurance limit is very much lower specially at high stresses (see fig.3)

The nitriding temperature appears to be major influencing factor on the fatigue properties. Nitriding at $570 \mathrm{C}$ in $10 \% \mathrm{NH} 3$ for a long period is assumed to produce modest compressive stress at the surface and reduce core strength. To confirm the effect of nitriding temperature and time on the fatigue properties, a fatigue test was carried out using specimens that were first tempered at $600 \mathrm{C}$ for $1 \mathrm{~h}$, and then retempered at $570 \mathrm{C}$ for $48 \mathrm{~h}$., the latter treatment was used to simulate the nitriding temperature and time of the specimens nitrided in $10 \% \mathrm{NH} 3$. The $\mathrm{S}-\mathrm{N}$ curves for the above treatment and the standard tempering treatment are shown in Fig 4. there is no apparent effect on the fatigue limit, but the endurance limit decreased significantly. Comparing the fatigue curves of $570 \mathrm{C}$ nitrided specimens with the non-nitrided specimens, the nitrided ones have a lower endurance limit.

The inferior fatigue behavior due to nitriding at a high temperature in a low $\mathrm{NH} 3$ concentration is attributed to the increase in the residual tensile stress 
of the core to counterbalance the residual compressive stress in the case. This would adversely affect the fatigue performance, especially at high stress levels. Whereas nitriding at $520 \mathrm{C}$ does not soften the core and produces very high residual compressive stresses at the surface, a combination which is favourable in terms of improving fatigue properties.

\section{Fractography of the Fatigue Specimens}

Figure (4). Illustrates typical optical micrographs of the fracture surfaces taken from representive non-nitrided and nitrided samples. There are clear differences in the features of the fatigue fracture between the tempered and the nitrided specimens.

The fracture surface of the as - tempered specimens always indicated that crack initiation occurred at the surface and in some specimens occurred at more than one place at the surface. Fig4a, shows at least two origins, at the bottom and left hand side of the cross-section. Final failure has occurred due to micro void coalescence.

No sub-surface cracks were observed in any fatigue fracture of the tempered specimens.

Unlike tempered material, the fracture surface topography of the nitrided samples was always flat and perpendicular to the longitudinal axis of the specimens.. The macrostructure shows the presence of three distinct regions. The outer ring corresponds to the brittle fracture of the nitrided case that failed by fatigue. The annulus corresponds to part of the core that failed by fatigue, and the central circular region corresponds to the final failure of the core.

The nitrided case fracture of specimens nitrided at $520 \mathrm{C}$, both in $80 \%$ and $30 \% \mathrm{HN} 3$, showed a pure transgranular fracture at all stress levels.Fig.5 is a scanning electron micrograph taken from the case area showing trasgranular cracking with characteristic tearing. In all specimens the outermost region of the nitrided case is smoother than the interior indicating that the fractures were initiated at the surface.

In specimens that were nitrided at $570 \mathrm{C}$ in $10 \% \mathrm{HN} 3$, the case fracture is different to that observed in specimens nitrided at 520C. A combination of both transgranular and intergranular fracture mode occurs, which is clearly illustrated in fig.6, again there is no apparent effect on the appearance of the fracture surfaces as a function of applied stress. 
مجلة العلوم الهندسية_العدد الثنان-2006

The depth of the brittle case fracture is constant at all stress levels, and in each nitriding condition the brittle fracture is approximately equal to the nitrided depth revealed by etching, and not the hardening depth. Table (3) lists the average depth revealed by micro hardness readings and by etching in oberhoffer's reagent compared with the depth of brittle fracture under each nitriding condition.

The typical microstructure of the final failure region of the core, in which the fracture occurred by microvoid coalescence, is in all cases similar to that shown in fig. 7. The area of the final fracture decreases with decreasing applied stress whilst the annular area increases. In many cases the position of this area is not located in the centre of the fracture. If the area is shifted to one side, it implies that crack propagation has started from the opposite side near to the sub-surface crack. Once the surface crack reaches the sub-surface crack initiated by intermedtalic inclusion, and then crack propagation jumps into the core, whereas at the other regions of the surface the crack has not yet reached the case/ core interface. In fracture surfaces that contain sub-surface cracks, the final failure area was always shifted from the centre to the side opposite to the sub-surface crack. This means that the later aided crack propagation within the core area.

The sub-surface cracks that are initiated by inclusion immediately below the nitrided case region were only observed in specimens nitrided at 520 in $30 \%$ or $80 \% \mathrm{HN} 3$, such cracks were not observed in any specimen nitrided at $570 \mathrm{C}$ in $10 \% \mathrm{HN} 3$, the position of the inclusions that initiated the crack, are always a similar distance from the surface in specimens that are nitrided under the same conditions irrespective of the applied stress. The measured figures are approximately $\sim 0.6 \mathrm{~mm}$ for test pieces nitrided at $520 \mathrm{C}$ in $80 \% \mathrm{NH} 3$ for $24 \mathrm{~h}$. the figures are slightly greater than the limit of hardening depth in both conditions ( see table 3). And in this region the tensile stress is maximum, and it appears to be high enough to promote sub-surface crack (S.S.C) at intermetalic inclusions in which the latter act as stress raisers.

It appears that the fatigue life may be affected by the size of the subservice crack as an example, in table 4, by comparing specimen (2) which has longer fatigue life at $1010 \mathrm{MPa}$ than specimen (3) with shorter fatigue life at $950 \mathrm{MPa}$, the sub-service crack diameter in the latter specimen is $0.73 \mathrm{~mm}$, which is much larger than that of the former specimen with diameter of 0.49 $\mathrm{mm}$. the same thing occurs with specimens (3) and (4) in table (5). However, it is well know that non-metallic inclusions impair the fatigue strength of steel. The reduction in strength arises from the stress concentration introduced by 
inclusion. The influence of inclusions on the fatigue strength depends primarily on their size, shape and their resistance to deformation and on their orientation to the stress acting on the metal. The influence of inclusions in reducing the fatigue strength is more significant in high strength steel (10), than in low strength steel (11).

The presence of sub-surface fatigue racks in nitrided material has been reported previously by several authors $(4,7,12,13)$. Bardgett (4) reported that fatigue life of the nitrided steel was found to be shorter in materials containing a high inclusion count. Jones and Martin (7) found that failure of nitrided EN41B steel, in the region of fatigue limit can be controlled by cracks propagating from non-metallic sub-surface, inclusion, when subjected to direct stress.

\section{Conclusions}

The fatigue behavior of the nitrided En41A depends on the quality of the nitrided case in terms of hardness, depth and microstructure.

1. Nitriding at 520C improves fatigue properties due to the high residual stress level of his nitrided layer.

2. The inferior fatigue properties at $570 \mathrm{C}$ are due to the low residual stress level and due to the embitterment effect.

3. The sub-surface cracks initiated by inclusions can reduce the fatigue life of the nitriaded. 


\section{References}

[1]Mailander, , R .Tech. Mitt. Krup. 1933, 2, 53.

[2] Sutton, H. Metal treatment, 1936, 2, 89.

[3] Bardgett, W.E. Metal Treatment, 1943, 10, 87.

[4] Sawert, W. Z. Ver. Dtsch. Ing. 1943, 87, 609.

[5] Tauscher, H. $\quad$ Neue - Hutt, 1974, 19, 228.

[6] JonHengstenburg. O. Zeitschrift des Vereines deutscher.

[7] Mailandes, B.K. Martin, J. W. Metal Technology. Jul. 1978, 217.

[8] Jack, D.H.Winnik, S. Heat Treatment ' 79, 196, 169.

[9] H. Wiegand Revue de Matallurgie, 1978, 45, 105.

[10] Frith, P.H. ' Int. conf. on Fatigue' Ist Mech. Eng, 1956, 462.

[11]Teed, P.L. Symposium: Fatigue and Fracture of Materials. M.I.T.J wiley, New York, 1950, 252.

[12] Wellinger, K. Archive Eisench, 1952 23, 203.

[13] Jones, P.K Martin, J.W. Metal Technology Nov. 1977, 51. 


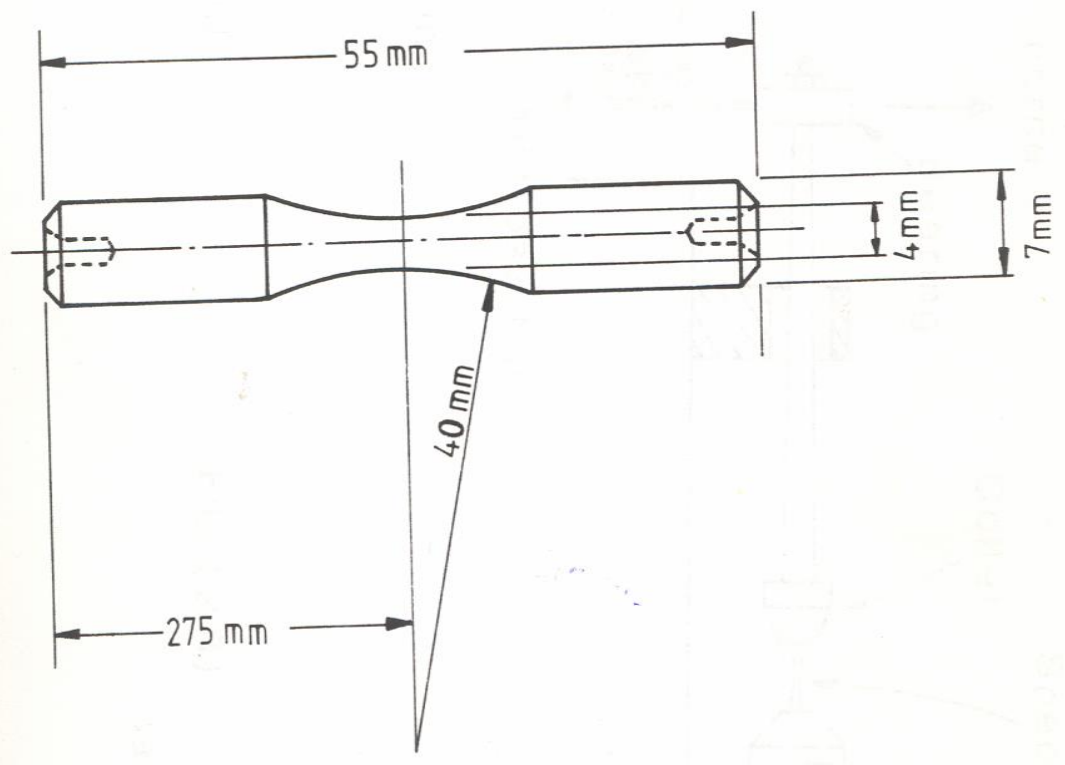

Figure (1) Schematic drawing of Rolls Royce Type Fatigue Specimen.

Table (1) Chemical Composition of En41Asteel

\begin{tabular}{|l|l|l|l|l|l|l|l|}
\hline Element & $\mathrm{C}$ & $\mathrm{Cr}$ & $\mathrm{Al}$ & $\mathrm{Mo}$ & $\mathrm{Ni}$ & $\mathrm{Si}$ & $\mathrm{Mn}$ \\
\hline Wt.\% & 0.33 & 0.65 & 1.04 & 0.2 & 0.39 & 0.3 & 0.59 \\
\hline
\end{tabular}


مجلة العلوم الهندسية_العدد الثاني-2006

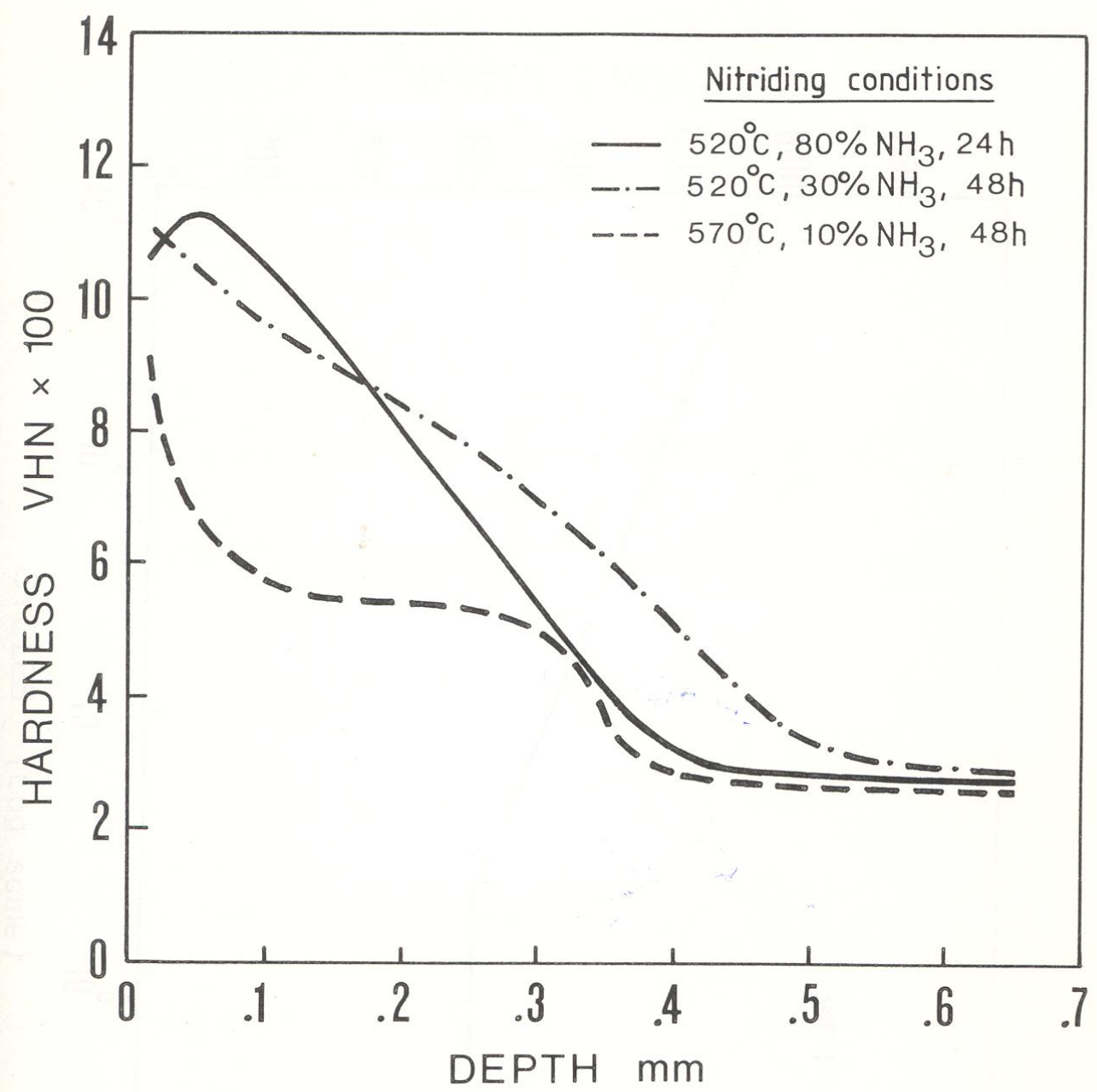

Figure (2) Hardness profiles of the Nitrided Fatigue Specimens for the Conditions Shown Above. 
Table (2) Data for Nitrided En41A Fatigue Specimens.

\begin{tabular}{|l|c|c|c|c|}
\hline Nitriding conditions & $\begin{array}{c}\text { Case } \\
\text { depth mm }\end{array}$ & $\begin{array}{c}\text { White } \\
\text { layer depth } \\
\mathrm{mm}\end{array}$ & $\begin{array}{c}\text { Maximum } \\
\text { hardness VHN }\end{array}$ & $\begin{array}{c}\text { Core } \\
\text { hardness } \\
\text { VHN }\end{array}$ \\
\hline $\begin{array}{l}520 \mathrm{C}, 80 \% \\
\mathrm{HN}\end{array}, 24 \mathrm{~h}$. & 0.425 & 25 & 11.30 & 300 \\
\hline $\begin{array}{l}520 \mathrm{C}, 30 \% \\
\mathrm{NH}_{3}, 48 \mathrm{~h} .\end{array}$ & 0.550 & - & 11.00 & 290 \\
\hline $570 \mathrm{C} 10 \% \mathrm{HN}_{3}$ & 0.450 & - & 920 & 270 \\
\hline $48 \mathrm{~h}$
\end{tabular}

Table (3) Showing the Nitrided Case Depth Revealed by Fatigue Fracture is Similar to that Revealed by Etching.

\begin{tabular}{|l|c|c|c|}
\hline Nitriding conditions & $\begin{array}{l}\text { Hardness } \\
\text { depth } \\
\text { mm }\end{array}$ & $\begin{array}{l}\text { Etching } \\
\text { depth mm }\end{array}$ & $\begin{array}{c}\text { Fatigue } \\
\text { depth mm }\end{array}$ \\
\hline $520 \mathrm{C}, 80 \% \mathrm{HN} 3,24 \mathrm{~h}$ & 0.425 & 0.35 & 0.32 \\
\hline $520 \mathrm{C}, 30 \% \mathrm{HN} 3,48 \mathrm{~h}$ & 0.55 & 0.45 & 0.45 \\
\hline $570 \mathrm{C}, 80 \% \mathrm{HN} 3,24 \mathrm{~h}$ & 0.45 & 0.63 & 0.66 \\
\hline
\end{tabular}


Table (4) Fatigue Data and Sub-Surface Fatigue Crack Dimensions for Specimens Nitrided at $520 \mathrm{C}$ in $30 \% \mathrm{HN} 3$ For 48h

\begin{tabular}{|c|l|l|l|}
\hline No. & S MPa & N cycles & S.S.C diameter mm \\
\hline 1. & 1100 & 216.000 & 0.43 \\
\hline 2. & 1010 & 647.400 & 0.49 \\
\hline 3. & 950 & 425.900 & 0.73 \\
\hline 4. & 950 & 602.100 & 0.60 \\
\hline 5. & 885 & 3.503 .500 & 0.67 \\
\hline
\end{tabular}

Table (5) Fatigue Data and Sub-Surface Fatigue Crack Diameter for Specimens Nitrided at $520 \mathrm{C}$ in $80 \%$ HN3 For $24 \mathrm{~h}$

\begin{tabular}{|c|c|c|c|}
\hline No. & S MPa & N cycles & S.S.C diameter mm \\
\hline 1. & 1100 & 124.100 & 0.41 \\
\hline 2. & 1025 & 191.300 & 0.63 \\
\hline 3. & 950 & 314.000 & 0.47 \\
\hline 4. & 900 & 271.000 & 0.77 \\
\hline 5. & 850 & 1.569 .100 & 0.69 \\
\hline
\end{tabular}




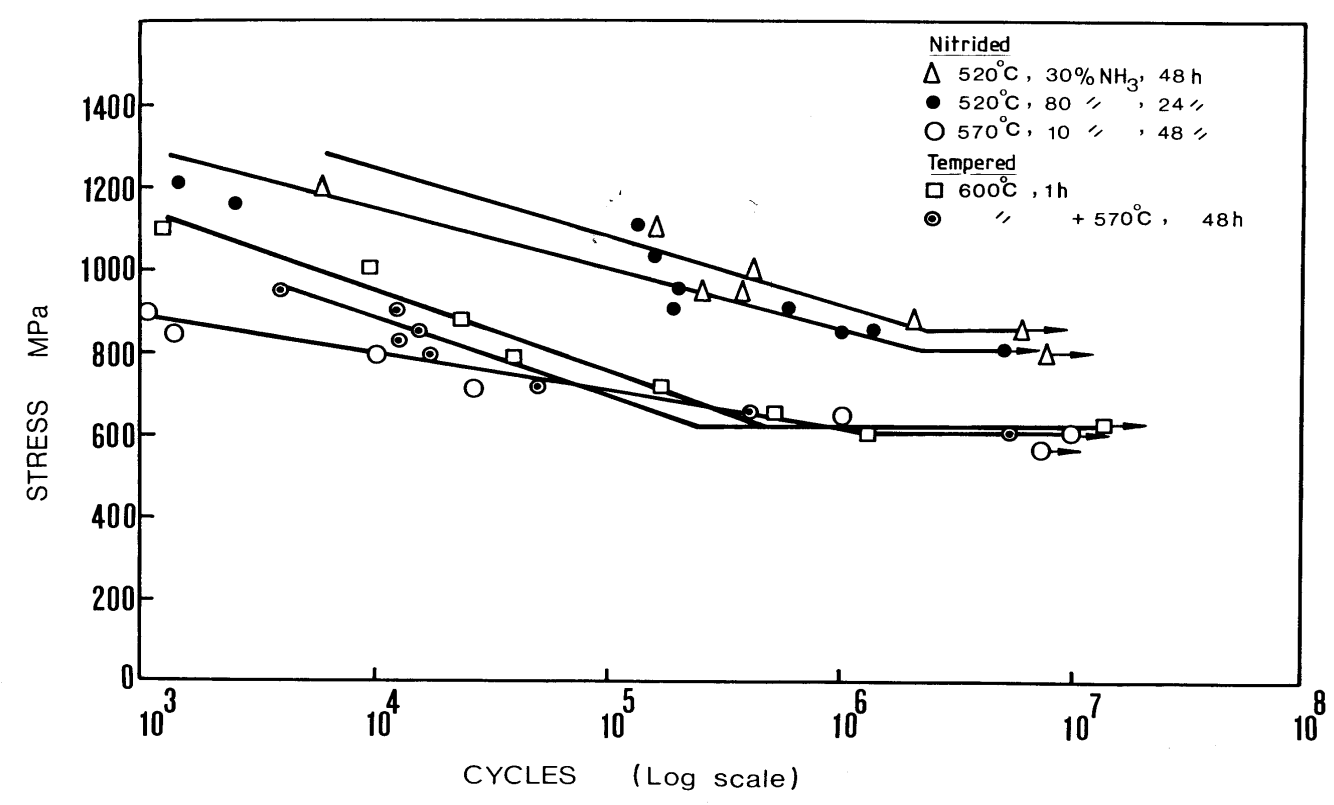

Figure (3): S-N curves for the Nitrided and as - Tempered Specimens. 


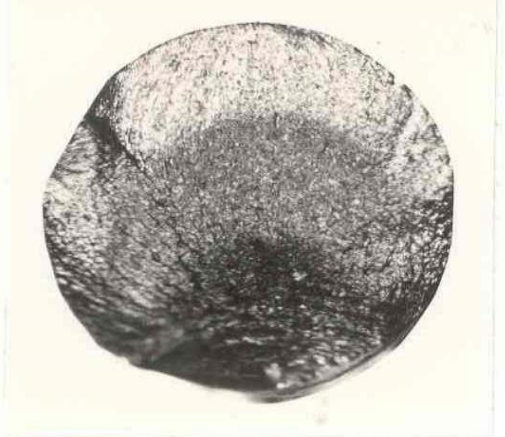

a) Tempered $600^{\circ} \mathrm{C}, 1 \mathrm{~h}$

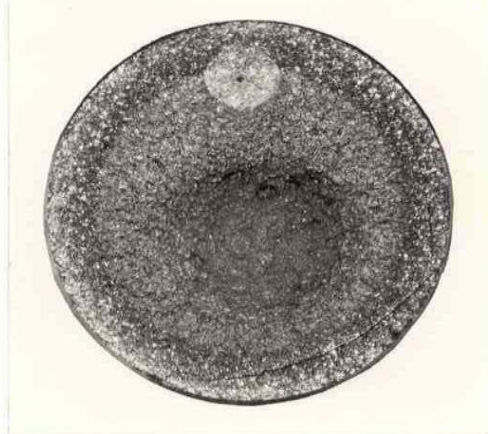

b) Nitrided $520^{\circ} \mathrm{C}, 30 \% \mathrm{NH}_{3}, 48 \mathrm{~h}$

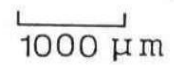
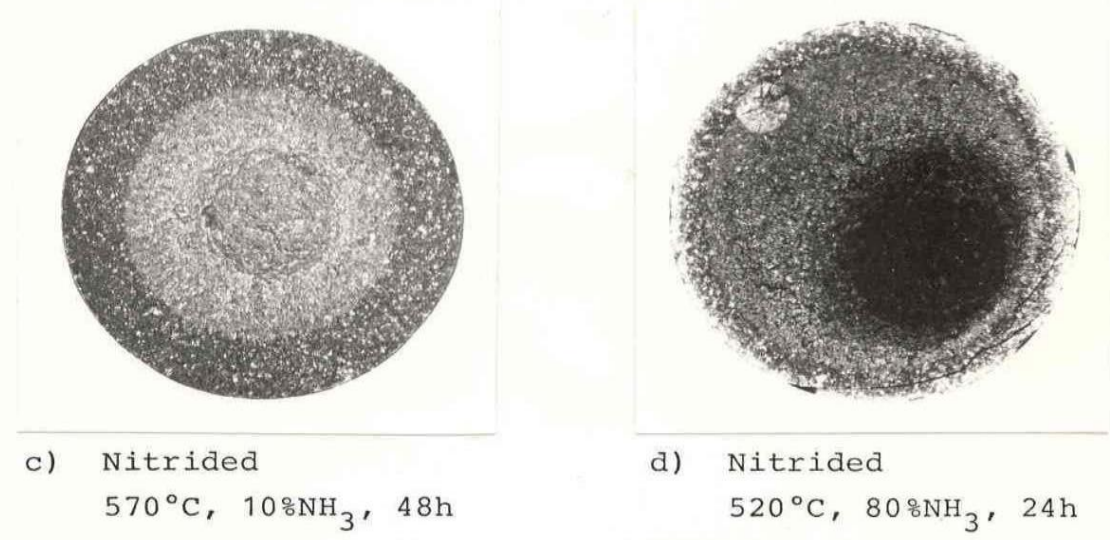

Figure (4): Optical Micrographs Showing Characteristics Fracture Surfaces of the Fatigue Specimens. 


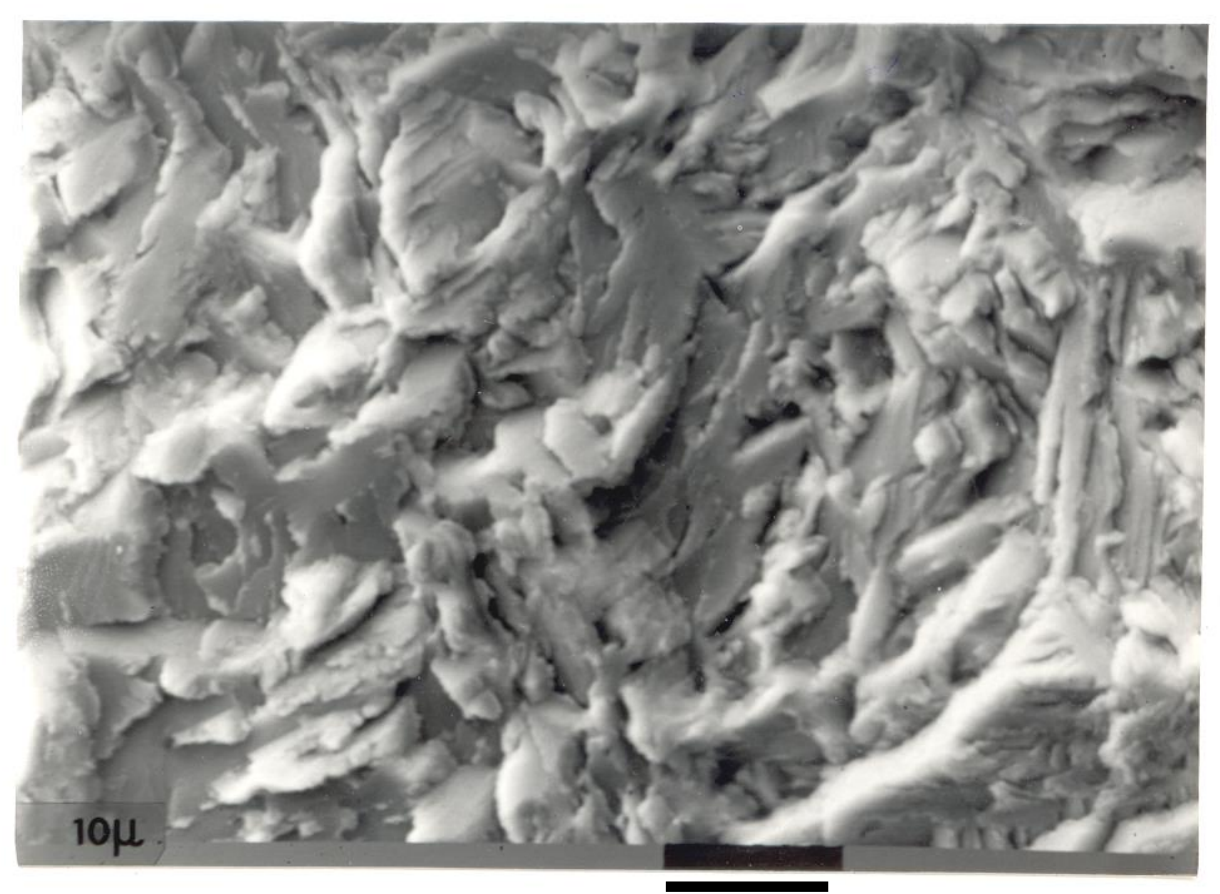

$10 \mu$

Figure (5): Scanning Electron Micrograph of Fatigue Fracture of a Nitrided En41A Showing Transgranular Tearing of the Nitrided Layer 
مجلة العلوم الهندسية_العدد الثاني-2006

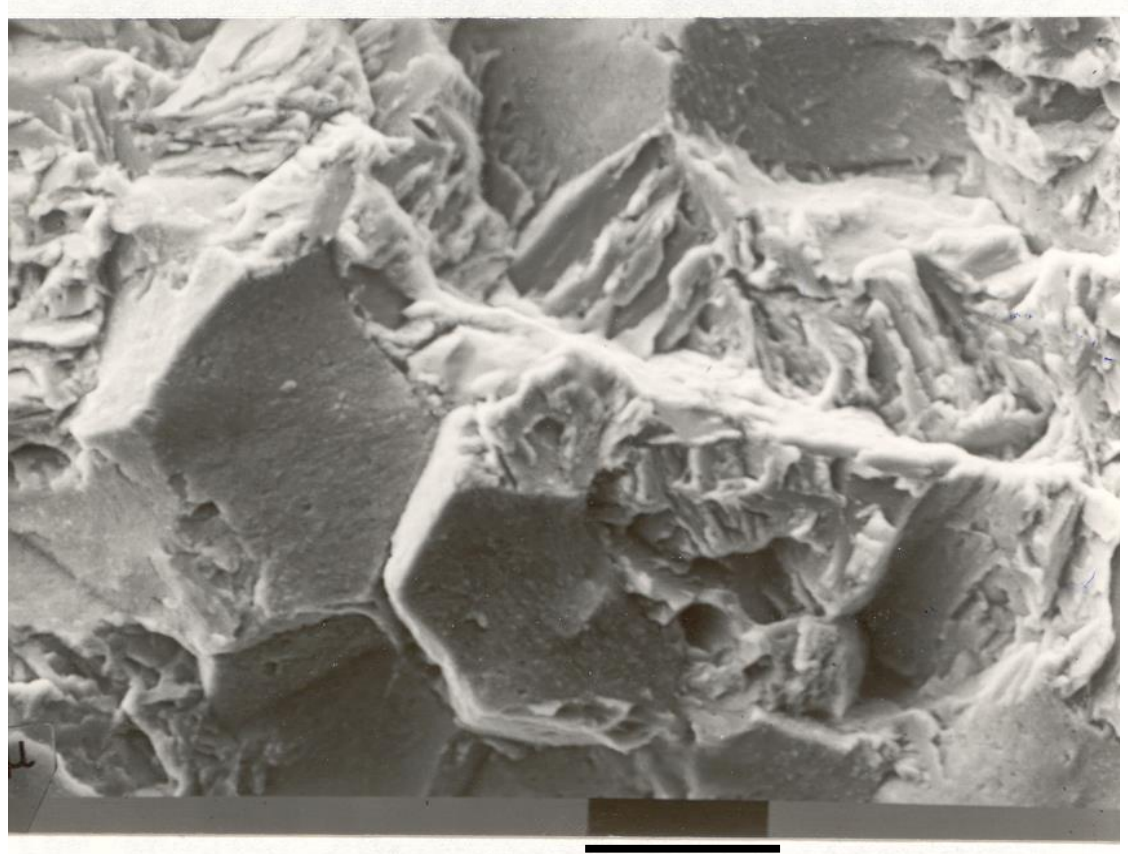

$10 \mu$

Figure (6): Scanning Electron Micrograph of En41A Nitried at $570^{\circ} \mathrm{C}$ in $10 \% \mathrm{NH}_{3}$ for $48 \mathrm{~h}$, showing a combination of transgranular tearing and Intergranular Taceting. 


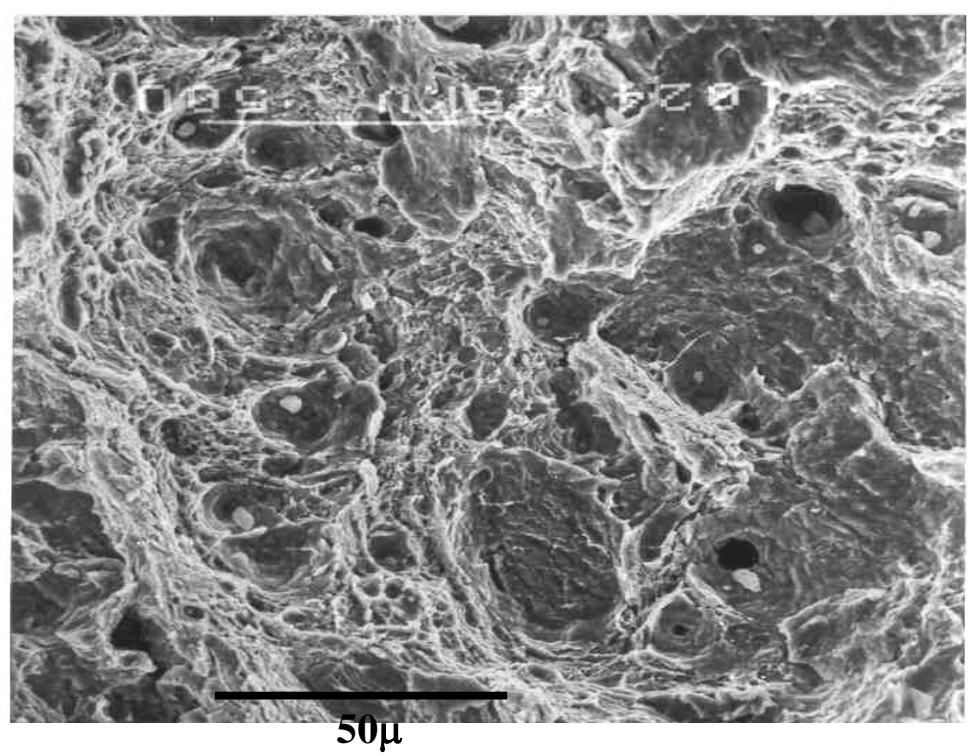

Figure (7): Scanning Electron Micrograph for the Final Fatigue Fracture Area Showing Micro Voids Coalescenc
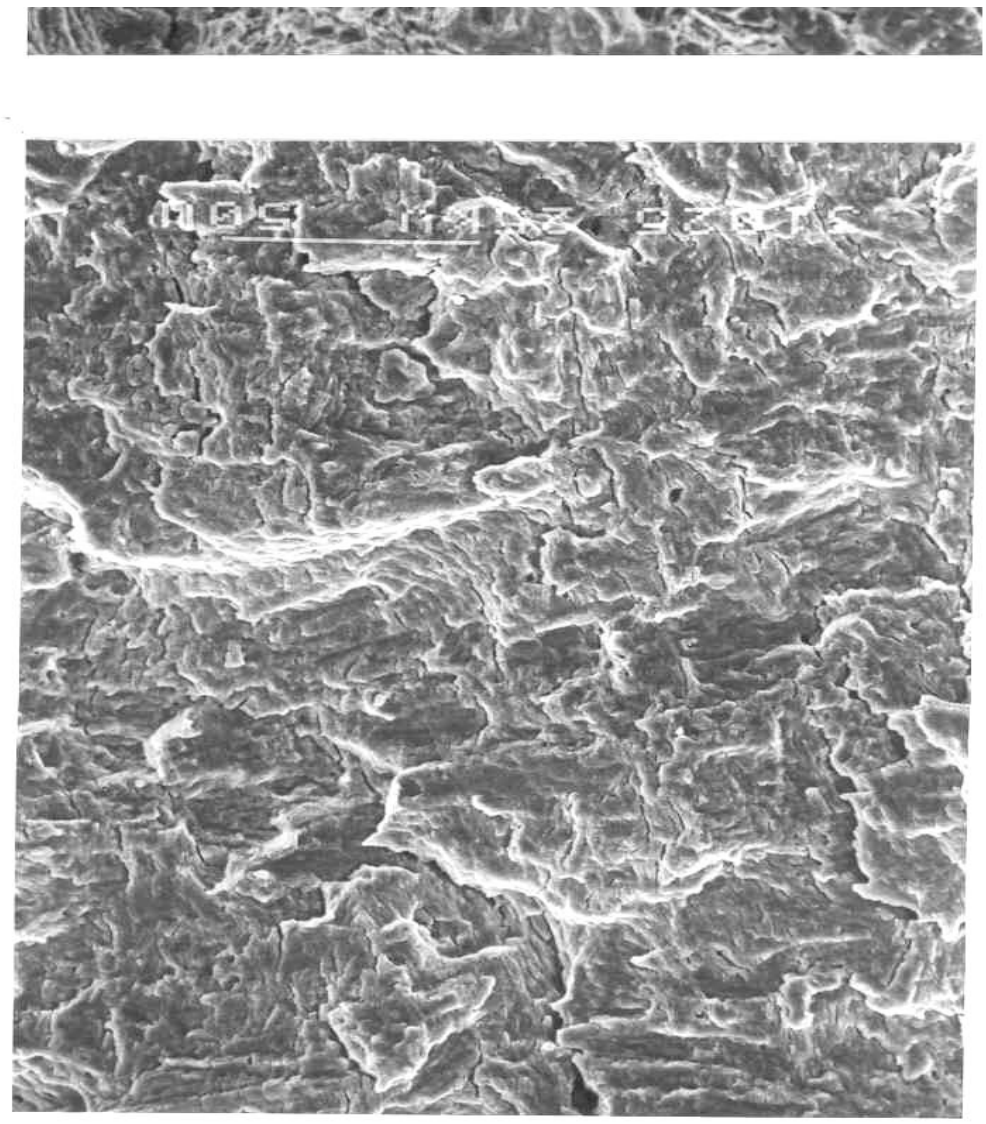